FERREIRA, C.G.T., GAMELEIRA, J.S. e AHID, S.M.M. Levantamento de ectoparasitos em ovinos no Município de Jardim do Seridó, Rio Grande do Norte, Brasil. PUBVET, Londrina, V. 5, N. 18, Ed. 165, Art. 1114, 2011.

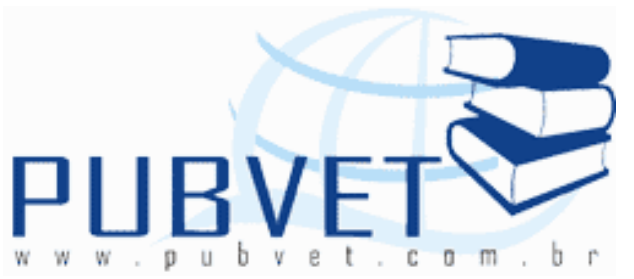

PUBVET, Publicações em Medicina Veterinária e Zootecnia.

\title{
Levantamento de ectoparasitos em ovinos no Município de Jardim do Seridó, Rio Grande do Norte, Brasil
}

\section{Caroline Gracielle Torres Ferreira ${ }^{1}$, Jucélio da Silva Gameleira ${ }^{2}$, Silvia Maria Mendes Ahid $^{3}$}

${ }^{1}$ Médica Veterinária. e-mail: caroline-torres@hotmail.com

${ }^{2}$ Discente de Medicina Veterinária, Universidade Federal Rural do Semi-Árido (UFERSA). e-mail: jucelio gameleira@hotmail.com

${ }^{3}$ Docente do Departamento de Ciências Animal, coordenadora do Laboratório de Parasitologia Animal da UFERSA. e-mail: ahid@ufersa.edu.br

\section{Resumo}

O Brasil tem um grande mercado potencial para produtos derivados da pele de pequenos ruminantes domésticos. Entretanto na exploração ovina as ectoparasitoses acarretam perdas econômicas, seja devido à mortalidade decorrente de altas infestações, ou indiretamente, por meio da irritação causada nos animais, levando-os a queda da produtividade e predisposição a infecções secundárias. Dentre as ectoparasitoses, a pediculose causada por piolhos mastigadores é a mais freqüente, que embora se tenha progressos tecnológicos no seu controle, vêm aumentando o risco de comprometimento da qualidade do couro, marcados pela intensa descamação da pele e possibilidade de parasitismo misto. Considerando a importância do conhecimento dos ectoparasitos dos ovinos, o presente trabalho objetiva identificar os 
FERREIRA, C.G.T., GAMELEIRA, J.S. e AHID, S.M.M. Levantamento de ectoparasitos em ovinos no Município de Jardim do Seridó, Rio Grande do Norte, Brasil. PUBVET, Londrina, V. 5, N. 18, Ed. 165, Art. 1114, 2011.

ectoparasitos que acometem os ovinos no município de Jardim do Seridó, Rio Grande do Norte, Brasil. Foram examinados 1000 ovinos através de inspeção e palpação manual aleatórias em $10 \%$ desses animais, independente do sexo, recolhendo-se os ectoparasitos encontrados no corpo. Os espécimes coletados foram acondicionados em frascos individuais, por hospedeiro amostrado, contendo álcool a $70^{\circ} \mathrm{GL}$ como líquido conservador, para posterior identificação. No laboratório de Parasitologia Animal da Universidade Federal Rural do Semi-Árido (UFERSA) foi realizada a identificação com auxílio de estereomicroscópio, utilizando-se chave dicotômica, segundo a bibliografia especializada. Dos 1000 ovinos examinados, 600 (60,0\%) apresentaram infestação por Damalinia ovis, sendo 200 (33,3\%) animais jovens e 400 $(66,7 \%)$ animais adultos. Os resultados indicaram que os animais estudados são importantes hospedeiros de ectoparasitos, confirmando-se a presença disseminada de $D$. ovis corroborando com trabalhos em todo território nacional.

Palavras-chave: Phthiraptera, ovinos, nordeste

\title{
Survey of Ectoparasites in Sheep in the City of Jardim do Seridó, Rio Grande do Norte, Brazil
}

\begin{abstract}
Brazil has a large potential market for products derived from the skin of small domestic ruminants. However in the ovine infestation cause economic losses, either due to high mortality due to infestation, or indirectly, caused by irritation in animals, causing them to fall in productivity and susceptibility to secondary infections. Among the infestation, pediculosis caused by lice is the most frequent, although it has been technological advances in their control, have increased the risk of compromising the quality of leather, marked by intense scaling of the skin and the possibility of mixed parasitism. Considering the importance of knowledge of the ectoparasites of sheep, this study aims to identify the parasites that affect sheep in the city of Jardim do Seridó, Rio
\end{abstract}


FERREIRA, C.G.T., GAMELEIRA, J.S. e AHID, S.M.M. Levantamento de ectoparasitos em ovinos no Município de Jardim do Seridó, Rio Grande do Norte, Brasil. PUBVET, Londrina, V. 5, N. 18, Ed. 165, Art. 1114, 2011.

Grande do Norte, Brazil. 1000 sheep were examined by visual inspection and random manual palpation in $10 \%$ of these animals, regardless of sex, collecting the ectoparasites found in the body. The specimens were placed in individual bottles, per host sampled, containing alcohol $70^{\circ} \mathrm{GL}$ conservative as liquid for further identification. In the laboratory of Animal Parasitology of the Federal Rural University of Semi-Arid (UFERSA) was performed to identify with a stereomicroscope, using a dichotomous key, according to the literature. Of the 1000 sheep examined, $600(60.0 \%)$ had Damalinia ovis infestation, 200 (33.3\%) young animals and $400(66.7 \%)$ adult animals. The results indicated that the animals are important hosts for ectoparasites, confirming the widespread presence of $D$. ovis corroborating jobs nationwide.

Keywords: phthiraptera, sheeps, northeast.

\section{INTRODUÇÃO}

O Brasil tem um grande mercado potencial para produtos derivados da pele de pequenos ruminantes domésticos, apresentando, também, condições favoráveis para a produção de calçados e vestuário em quantidades suficientes para suprir a demanda interna e gerar excedentes exportáveis (Brito et al., 2005). A ovinocultura brasileira vem crescendo em todas as regiões do País, tendo, inclusive, se destacado nas regiões Nordeste e Centro-Oeste.

Entretanto na exploração ovina as ectoparasitoses acarretam perdas econômicas, seja devido à mortalidade decorrente de altas infestações, ou indiretamente, por meio da irritação causada nos animais, levando-os a queda da produtividade e predisposição a infecções secundárias (Maciel et al., 2006). Dentre as ectoparasitoses, causadas por artrópodes, as mais importantes que acometem os caprinos e ovinos são a pediculose, sarna e miíases. A pediculose causada por piolhos mastigadores é a mais freqüente, que embora se tenha progressos tecnológicos no seu controle, vêm aumentando o risco de comprometimento da qualidade do couro, marcados pela intensa descamação da pele e possibilidade de parasitismo misto, pelos tipos hematófagos. 
FERREIRA, C.G.T., GAMELEIRA, J.S. e AHID, S.M.M. Levantamento de ectoparasitos em ovinos no Município de Jardim do Seridó, Rio Grande do Norte, Brasil. PUBVET, Londrina, V. 5, N. 18, Ed. 165, Art. 1114, 2011.

Considerando a importância do conhecimento dos ectoparasitos dos ovinos, o presente trabalho objetiva identificar os ectoparasitos que acometem os ovinos no município de Jardim do Seridó, Rio Grande do Norte, Brasil.

\section{MATERIAL E MÉTODOS}

O trabalho foi desenvolvido no município de Jardim do Seridó

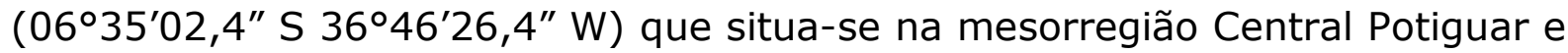
na microrregião Seridó Oriental e que apresenta um rebanho de ovinos com mais 7685 animais. Os animais examinados eram provenientes de propriedades de pequenos e médios criadores de criação extensiva.

Foram examinados 1000 ovinos através de inspeção e palpação manual aleatórias em $10 \%$ desses animais, independente do sexo, recolhendo-se os ectoparasitos encontrados no corpo. Os espécimes coletados foram acondicionados em frascos individuais, por hospedeiro amostrado, contendo álcool a $70^{\circ} \mathrm{GL}$ como líquido conservador. No laboratório de Parasitologia Animal da Universidade Federal Rural do Semi-Árido (UFERSA) foi realizada a identificação com auxílio de estereomicroscópio, utilizando-se chave dicotômica, segundo a bibliografia especializada.

\section{RESULTADOS E DISCUSSÃO}

Dos 1000 ovinos examinados, $600(60,0 \%)$ apresentaram infestação por Damalinia ovis. Observou-se que ao exame clínico dos ovinos parasitados por $D$. ovis no Jardim do Seridó-RN, os animais apresentaram inquietação e prurido corroborando com os sinais clínicos observados em outros estudos (Bezerra et al., 2007). As ectoparasitoses são causas freqüentes de prejuízos econômicos a ovinocaprinocultura, pois ocasionam aos animais stress, irritação, diminuição do apetite, diminuição da produção e da produtividade, além da desvalorização na comercialização da pele.

Em relação à idade desses animais, dos 300 animais jovens examinados 
FERREIRA, C.G.T., GAMELEIRA, J.S. e AHID, S.M.M. Levantamento de ectoparasitos em ovinos no Município de Jardim do Seridó, Rio Grande do Norte, Brasil. PUBVET, Londrina, V. 5, N. 18, Ed. 165, Art. 1114, 2011.

$200(33,3 \%)$ estavam parasitados enquanto que dos 700 adultos, $400(66,7 \%)$ apresentaram positivos para a presença de piolho.

A pele ou lã de ovinos, dependendo do peso do animal e da flutuação do mercado, pode representar até $25 \%$ do valor do animal. Para a região Nordeste que detém em torno de $51 \%$ do rebanho ovino nacional, isso representa uma grande fonte econômica, sobretudo para o sertão onde se concentra a maior parte dos rebanhos (Coelho et al., 2004). Em ovelhas infestadas artificialmente com piolho, de $D$. ovis, houve redução da lã em 0,3$0,8 \mathrm{~kg}$ por ovelha, mas não afetou o peso do animal, o que representou uma perda de renda para o criador, de $U \$ \$ 0,72$ a 1,92 para cada ovelha infestada, concordando com informações similares dos proprietários da área estudada, os quais afirmavam maiores perdas econômicas devido ao ectoparasitismo (Almeida, 2006).

Infestações por $D$. ovis freqüentemente ocorrem alterações no ganho de peso, qualidade de lã ou pele. Dessa forma, ovelhas tratadas produzem em média $34 \%$ a mais lã que o grupos infestados sem tratamento (animal controle) e, a lã da ovelha tratada é de uma qualidade melhor. A média do ganho de peso vivo nos grupos tratados também é superior que em grupos sem tratamento. Quanto à hipersensibilidade, reações dérmicas de extratos (antígenos) de Muscidae e Damalinia são achados consistentes para D. ovis, este fato sugere que reações da pele devido à infestação com piolhos podem influenciar na suscetibilidade de ovinos em relação a outros ectoparasitos (Almeida, 2006).

Os resultados obtidos mostraram-se superiores aos obtidos no estado de São Paulo e Maranhão onde observou-se a prevalência de 13,8\% e 3,4\% para o parasitismo por $D$. ovis, entretanto nestes mesmos Estados constatou a ocorrência de piolhos e outros ectoparasitos de ovinos, resultados estes que não condizem com os encontrados no município de Jardim do Seridó.

Os animais com diagnóstico positivo de pediculose devem ser separados e tratados, pois a transmissão se dá pelo contato direto entre animais doentes e sadios do rebanho. Crawford et al. (2001) num estudo sobre transmissão de 
FERREIRA, C.G.T., GAMELEIRA, J.S. e AHID, S.M.M. Levantamento de ectoparasitos em ovinos no Município de Jardim do Seridó, Rio Grande do Norte, Brasil. PUBVET, Londrina, V. 5, N. 18, Ed. 165, Art. 1114, 2011.

piolhos em ovinos, observaram outras formas de transmissão da pediculose, além do contato direto, a exemplos de equipamentos, cercas, instalações contaminadas, lã e calçados de tosquiadores, funcionando como importantes meios de reinfestação, pois aumentam o tempo de sobrevivência do Damalinia ovis.

\section{CONCLUSÕES}

Notifica-se o parasitismo em ovinos por Damalinia ovis no município de Jardim do Seridó, corroborando com trabalhos em todo território nacional.

\section{REFERENCIAS}

ALMEIDA, V. F. Ação dos fungos Metarhizium anisopliae var. anisopliae (Metschnicoff 1879) Sorokin, 1883, M. flavoridae Gams \& Roszypal, Beauveria bassiana (Balsamo) Vuillemin, 1912, sobre Bovicola caprae (Phtiraptera: Mallophaga, Ewing 1936) em caprinos naturalmente infestados em clima de semi-árido. 2006. 50f. Dissertação (PósGraduação em Zootecnia -Sistemas Agrossilvopastoris no Semi-Árido) - Centro de Saúde e Tecnologia Rural, Universidade Federal de Campina Grande.

BEZERRA, A. C. D. S.; AHID, S. M. M.; VIEIRA, L. S. Prevalência de ectoparasitos em caprinos e ovinos do município de Mossoró, Rio Grande do Norte, Acta Veterinária Brasílica, 1 (2): $68,2007$.

BRITO, D. R. B.; SANTOS, A. C. G.; GUERRA, R. M. S. N. C. Ectoparasitos em rebanhos de caprinos e ovinos na microrregião do Alto Mearim e Grajaú, Estado do Maranhão. Revista Brasileira de Parasitologia Veterinária, 14 (2): 59-63, 2005.

COELHO, J. B. M; LINS, J. M.; ALVES, A. B.; SOARES, I. L. Influência da cor da pelagem na qualidade da pele caprina/ ovina curtida ao cromo. Disponível em: <http://www.capritec.com.br/art030911.htm>. Acesso em: 21 set 2010.

CRAWFORD, S.; JAMES, P. J.; MADDOCKS, S. Survival away from sheep and alternative methods of transmission of sheep lice (Bovicola ovis). Veterinary Parasitology, 94: 205$216,2001$.

MACIEL, F. C.; AHID, S. M. M.; MOREIRA, F. R. C. Manejo sanitário de caprinos e ovinos. In: LIMA, G. F. C et al. (Org) Criação Familiar de Caprinos e Ovinos no Rio Grande do Norte: orientações para viabilização do negócio rural. Natal: EMATER/EMPARN/EMBRAPA caprinos, p. 391-426, 2006. 